\title{
Benign Neurological Recovery with Low Recurrence and Low Peridural Fibrosis Rate in Pediatric Disc Herniations after Lumbar Microdiscectomy
}

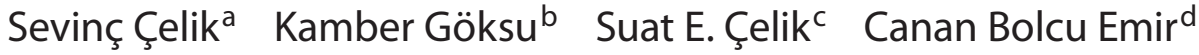 \\ a Department of Neurology, Fatih Sultan Mehmet Training and Research Hospital, ${ }^{b}$ Department of Radiology, \\ Zeynep Kamil Training and Research Hospital, and Departments of ${ }^{\mathrm{C}}$ Neurosurgery and ${ }^{\mathrm{d}}$ Neurology, \\ Okmeydanı Training and Research Hospital, Istanbul, Turkey
}

\section{Key Words}

Lumber disc herniation $\cdot$ Pediatric age $\cdot$ Lumbar microdiscectomy $\cdot$ Peridural fibrosis

\begin{abstract}
Lumbar disc herniation (LDH) is a very rare clinical entity in the pediatric age group, therefore only a few clinical studies have until now investigated the clinical behavior of pediatric LDH. The natural clinical history, postoperative neurological recovery with radiological follow-up and quality of life related to the disorder continue to be unknown. We prospectively planned and designed two groups of LDH patients scheduled for surgery in this study. The operations were performed by the same surgeon in a randomized fashion. The first group consisted of pediatric patients and the second group of adult patients. Both groups contained 32 cases. Postoperative neurological recovery was assessed using the visual analog scale and Aberdeen Low Back Pain Scale. Postoperative peridural fibrosis was also evaluated in postcontrast magnetic resonance sections. After 3 years of followup, all parameters were significantly better in the pediatric LDH group with no recurrence of the disease. The pediatric LDH group was postoperatively better than the adult group
\end{abstract}

both clinically and radiologically. Although LDH seems a catastrophic disease in the pediatric age group, the clinical picture and neurological recovery have a significantly more benign course than in adult patients even in operated cases.

Copyright ๑ 2012 S. Karger AG, Basel

\section{Introduction}

Lumbar disc herniation (LDH) surgery has constituted the major part of spinal surgery practice in the last decades. However, pediatric cases aged 18 years or younger are extremely rare. These cases only make up around $0.5 \%$ of all patients undergoing surgery for $\mathrm{LDH}$ [1]. The long-term outcome parameters of adult surgical series are quite well documented in the literature [2]. However, there are only a few studies emphasizing long-term outcome and recurrence rates in pediatric surgical series [35]. Although we have an adequate number of favorable results in the previous case studies in the literature to believe pediatric $\mathrm{LDH}$ has a benign nature, there are no comparative study results in the pediatric population so far [6-8].

\section{KARGER}

Fax +41613061234 E-Mail karger@karger.ch www.karger.com (c) 2012 S. Karger AG, Basel

$1016-2291 / 11 / 0476-0417 \$ 38.00 / 0$

Accessible online at: www.karger.com/pne
Suat E. Celik, MD

Göztepe Soyak sitesi, 58. Blok, Daire 1017

TR-34700 Göztepe, Istanbul (Turkey)

Tel. +90 216472 1699, E-Mail suaterolcelik@yahoo.com 


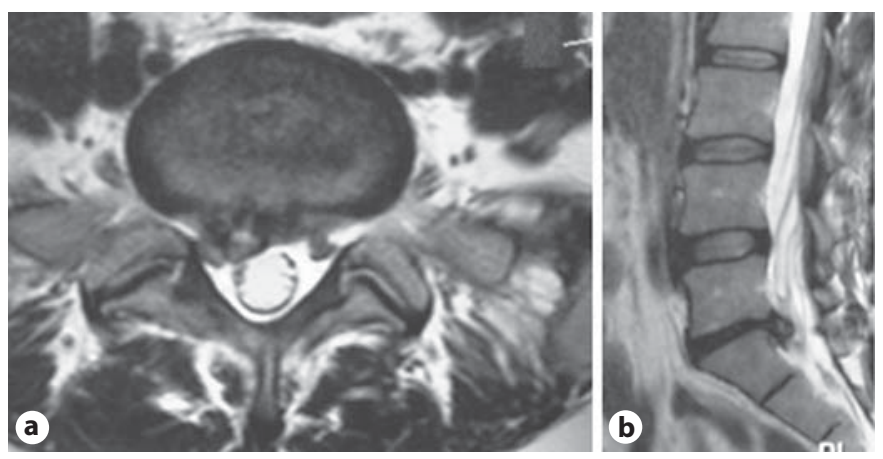

Fig. 1. A 14-year-old boy presented with right sciatica. There was Achilles' reflex loss on the right side. Preoperative $\mathrm{T}_{2}$-weighted axial slices (a) and sagittal slices (b) show extruded disc herniation at the L5-S1 level. There is no degenerative change in other disc spaces.

The clinical presentation of pediatric LDH is not much different than adult disease. The cardinal symptoms are low back pain and sciatalgia. Neuromotor deficits with hypoesthesia depending on the herniation segment with or without some reflex abnormalities suggest a radicular pathology. Diagnostic tests such as X-rays and magnetic resonance are confirmatory of the nerve root compromise $[1,9]$ (fig. 1a, b). Surgery might be an alternative option in the presence of neurological deficit or severe painful state despite intensive physical and drug therapy. The major differences between pediatric and adult LDH cases are nonspecific low back pain complaints, less sciatic pain and diagnostic difficulty of LDH in the pediatric age group because of its rarity. Painful pediatric cases may respond well to physical therapy and this should be the first-line treatment strategy if there is no neurological deficit [1].

The present study was performed by the authors to evaluate the long-term behavior of pediatric LDH after surgery. The recurrence rate and epidural fibrotic changes were compared to an adult surgical group operated on at the same time by the same surgical team to provide a prospective comparative analysis.

\section{Clinical Material and Methods}

\section{Patient Selection and Surgical Groups}

There were 32 patients aged 18 years or younger that underwent surgery for LDH between 1999 and 2009 in the pediatric group. All patients had been followed up. The mean follow-up period was 83 (11-130) months. A control group was generated randomly as an adult LDH group that underwent surgery at the same
Table 1. Demographic characteristics of the patients

\begin{tabular}{lll}
\hline & $\begin{array}{l}\text { Pediatric } \\
\text { group } \\
(\mathrm{n}=32)\end{array}$ & $\begin{array}{l}\text { Adult } \\
\text { group } \\
(\mathrm{n}=32)\end{array}$ \\
\hline Age & $15 \pm 3.2^{*}$ & $38 \pm 12$ \\
Sex (F/M) & $18 / 14$ & $12 / 20$ \\
Operative level & 16 & 15 \\
$\quad$ L4/L5 & 16 & 17 \\
$\quad$ L5/S1 & 21 & 19 \\
Disc pathology & 11 & 13 \\
$\quad$ Sequestration & 0 & $4^{*}$ \\
$\quad$ Extrusion & & \\
Recurrence & & $29^{*}$ \\
Degenerative changes & & \\
$\quad$ Black disc & & $24^{*}$ \\
$\quad \begin{array}{l}\text { Facet joint degeneration } \\
\quad \text { Operated level) }\end{array}$ & 0 & $17^{*}$ \\
$\quad \begin{array}{l}\text { Multilevel disc degeneration } \\
\text { Hypertrophy of yellow ligament }\end{array}$ & 0 & $12^{*}$ \\
\hline
\end{tabular}

* There is a significant difference between groups $(\mathrm{p}<0.05)$.

time as the pediatric cases and by the same surgeon. The first operated adult $\mathrm{LDH}$ case after every pediatric case was randomly recruited for the control group. Hence, the controls have a similar follow-up period and a similar clinical picture with the pediatric cases except their age. The demographic characteristics of both groups are presented in table 1 . All the medical conditions of patients including age at onset of the symptoms, duration of symptoms, previous analgesics and received physical therapies were recorded. The visual analog scale (VAS) scores and preoperative neurological findings, radiological studies, operative procedure and the operative findings such as root compromise by disc extrusion or sequestration were documented. Degenerative findings such as facet joint hypertrophy, multilevel disc degeneration, and hypertrophy of yellow ligament on preoperative MRI were also documented in both groups. All patients had been unresponsive to analgesic and muscle-relaxant drugs and physical therapy prior to the surgery. The postoperative clinical follow-ups were performed by the first author in the first and third postsurgical weeks, the second month and then every sixth month. Postoperative changes such as VAS scores of pain, condition of sciatic pain and neurological examination results were also recorded. The follow-up MRI was performed during the second month visit. A neuroradiology specialist evaluated the postcontrast sections both for the recurrence rates and fibrotic changes according to Ross et al. [10] for all patients (fig. 2a-d). In the postcontrast MRI, the contiguous axial sections (6 slices in 24 and 7 slices in 8 patients) at the operated disc level were observed. Each of the sections was further subdivided into four quadrants defined by perpendicular lines drawn from the center of the thecal sac. Quadrants $\mathrm{A}$ and $\mathrm{B}$ were the right and left anterior epidural space respectively, and encompassed the lateral recesses and existing roots. Quadrants C and D were the right and left posterior epidural spaces. The amount of epidural fibrosis was graded on a scale 
Fig. 2. A 15-year-old girl presented with left sciatica. The patient had $2 / 5$ power loss on left ankle dorsal flexion with L5 dermatome hypoesthesia. Preoperative axial (a) and sagittal (b) $\mathrm{T}_{2}$-weighted MRI scans show left extruded disc herniation at the L4-5 level. Postoperative follow-up $\mathrm{T}_{2}$ weighted scans $(\mathbf{c}, \mathbf{d})$ show removal of the extruded fragment and relaxation of the nerve root at the same level.
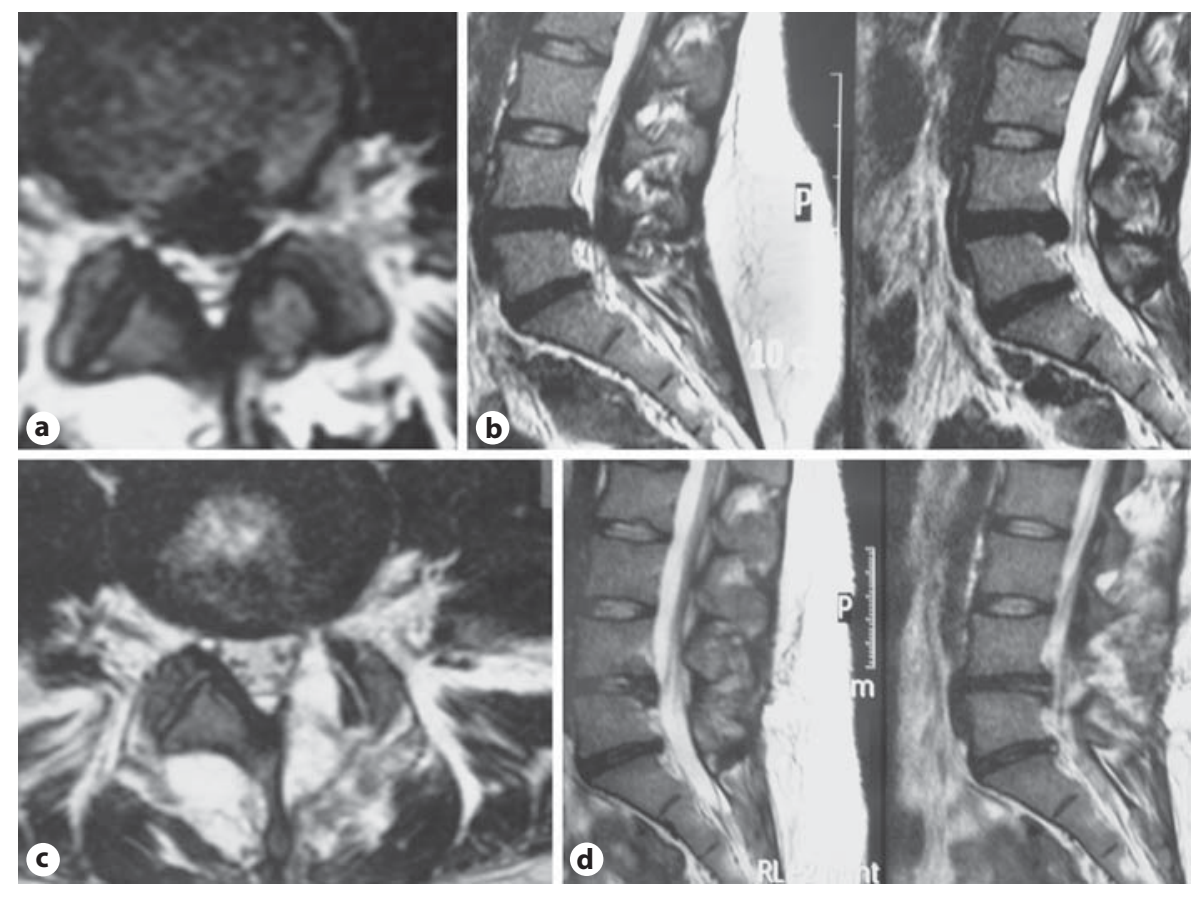

for each imaging section encompassing the operative level: $0=\mathrm{no} /$ trace scar; $1=>0$ and $\leq 25 \%$ of quadrants filled with scar; $2=>25$ and $\leq 50 \%$ of quadrants filled with scar; $3=>50$ and $\leq 75 \%$ of quadrants filled with scar; $4=>75$ and $\leq 100 \%$ quadrants filled with scar (fig. 3). Therefore, a total of 200 scores were obtained for each group. The clinical and radiological results of both groups were compared.

\section{Outcome Scales}

The patient's quality of life was evaluated by two measures: VAS and the Aberdeen Low Back Pain Scale (ALBPS).

\section{Statistical Analysis}

Student's t test was used to compare the two groups' pain scores and MRI findings. The results were considered statistically significant at $\mathrm{p}<0.05$.

\section{Clinical and Radiological Outcome}

The median follow-up period was 50 (36-65) months for the groups. Four recurrent disc herniations were observed in the adult group during follow-up. Two of the patients were reoperated, and the other 2 received physi$\mathrm{cal} /$ analgesic therapy. No recurrence was observed in the pediatric group.

All patients showed significant clinical and radiological recovery after the surgery in comparison with preoperative radiological results, VAS and ABPS scores. There
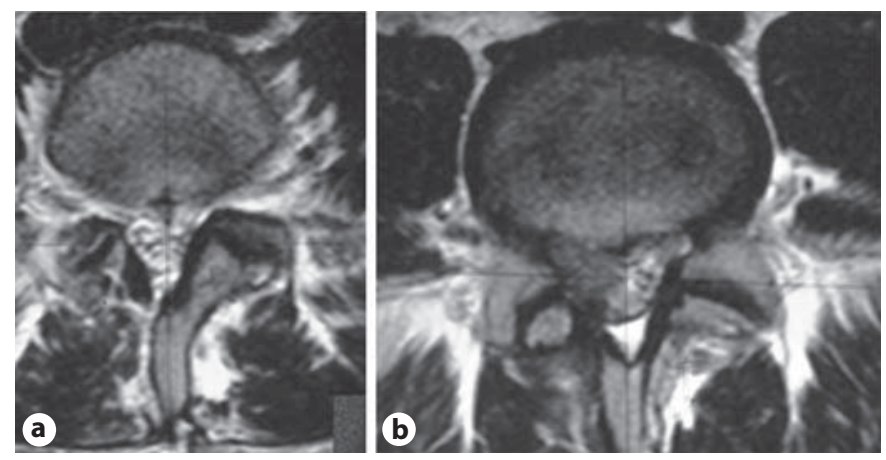

Fig. 3. Postoperative axial $\mathrm{T}_{2}$ image shows no peridural fibrosis in a pediatric case. It is grade 1 level according to Ross et al. [10], only 0 and $\leq 25 \%$ of quadrants filled with scar (a). The other postoperative axial $\mathrm{T}_{2}$ image shows severe peridural fibrosis in an adult case. It is grade 2 level according to the Ross et al. [10], 25 and $\leq 50 \%$ of quadrants filled with scar (b).

Table 2. MR grading results of both groups

\begin{tabular}{lll}
\hline $\begin{array}{l}\text { Pediatric group } \\
(200 \text { slices })\end{array}$ & $\begin{array}{l}\text { Adult group } \\
(200 \text { slices })\end{array}$ & F value \\
\hline $0.121 \pm 0.217^{*}$ & $0.761 \pm 0.428$ & 3.89
\end{tabular}

* There is a significant difference between groups $(\mathrm{p}<0.05)$. 
Table 3. VAS severity of both groups

\begin{tabular}{|c|c|c|c|}
\hline Variable & $\begin{array}{l}\text { Pediatric group } \\
(\text { mean } \pm S D)\end{array}$ & $\begin{array}{l}\text { Adult group } \\
(\text { mean } \pm S D)\end{array}$ & F value \\
\hline Preoperative value & $8.7 \pm 1.6^{*}$ & $8.4 \pm 1.5$ & 1.13 \\
\hline \multicolumn{3}{|l|}{ 1st week } & 5.06 \\
\hline Diff. from baseline & $6.1 \pm 4.3$ & $4.8 \pm 1.8$ & 5.7 \\
\hline \multicolumn{4}{|l|}{ 3rd week } \\
\hline Actual value & $2.3 \pm 0.7^{*}$ & $4.2 \pm 2.9$ & 17.1 \\
\hline Diff. from baseline & $6.4 \pm 3.9$ & $4.2 \pm 5.1$ & 1.71 \\
\hline \multicolumn{4}{|l|}{ 2nd month } \\
\hline Actual value & $0.2 \pm 0.4^{*}$ & $3.1 \pm 3.1$ & 60 \\
\hline Diff. from baseline & $8.5 \pm 5.3$ & $5.3 \pm 6.2$ & 1.36 \\
\hline \multicolumn{4}{|l|}{ 8th month } \\
\hline Actual value & $0.2 \pm 1.3^{*}$ & $2.8 \pm 3.6$ & 7.66 \\
\hline Diff. from baseline & $8.5 \pm 3.7$ & $5.6 \pm 5.4$ & 1.39 \\
\hline \multicolumn{4}{|l|}{14 th month } \\
\hline Actual value & $0.1 \pm 1.1$ & $3.3 \pm 1.3$ & 1.37 \\
\hline Diff. from baseline & $8.6 \pm 4.7$ & $5.1 \pm 3.8$ & 1.53 \\
\hline \multicolumn{4}{|l|}{ 20th month } \\
\hline Actual value & $0.1 \pm 0.2^{*}$ & $1.7 \pm 1.6$ & 64 \\
\hline Diff. from baseline & $8.6 \pm 0.6$ & $6.7 \pm 2.6$ & 18.77 \\
\hline
\end{tabular}

was no significant difference between the groups regarding postoperative early pain reduction. However, the rate of recurrent $\mathrm{LDH}$ (table 1) and postoperative fibrotic changes were significantly higher in the adult group as seen in the postoperative MRI sections (table 2). The other difference was the higher degree of degenerative changes in the adult group (table 1). Postoperative long-term VAS scores and ABPS were significantly better in the pediatric group after the third month (tables 3,4 ).

\section{Discussion}

The differences between adult and pediatric LDH are not well detailed in the context of the present knowledge in spinal surgery. To the authors' knowledge, the main reasons are the limited patient number of pediatric LDH patients and the relatively short follow-up periods. However, the general opinion for the pediatric cases is that they have a benign character with better prognosis than adult cases [1]. There are no prospective comparative data in the present literature. The possible reasons for the better prognosis are the low rate of mechanical back pain, relatively soft and elastic disc component at the herniated level, no compensation litigation problems and low rate
Table 4. ALBPS scores of both groups

\begin{tabular}{|c|c|c|c|}
\hline Variable & $\begin{array}{l}\text { Pediatric group } \\
(\text { mean } \pm S D)\end{array}$ & $\begin{array}{l}\text { Adult group } \\
(\text { mean } \pm S D)\end{array}$ & $\mathrm{p}$ value \\
\hline $\begin{array}{l}\text { Preoperative value } \\
\text { 1st week }\end{array}$ & $90.4 \pm 14.5$ & $89.1 \pm 17.2$ & 0.35 \\
\hline Actual value & $14.8 \pm 11.3$ & $16.7 \pm 9.2$ & 0.43 \\
\hline Diff. from baseline & $76.6 \pm 11.6$ & $72.4 \pm 11.8$ & 0.46 \\
\hline \multicolumn{4}{|l|}{ 3rd week } \\
\hline Actual value & $6.3 \pm 2.3$ & $13.1 \pm 7.7$ & 0.24 \\
\hline Diff. from baseline & $84.1 \pm 12.3$ & $76 \pm 13.4$ & 0.32 \\
\hline \multicolumn{4}{|l|}{ 2nd month } \\
\hline Actual value & $2.6 \pm 1$ & $9.5 \pm 6.7$ & 0.36 \\
\hline Diff. from baseline & $87.8 \pm 13.1$ & $79.6 \pm 13.7$ & 0.40 \\
\hline \multicolumn{4}{|l|}{ 8th month } \\
\hline Actual value & $2.1 \pm 1.7^{*}$ & $14.1 \pm 9.3$ & 0.06 \\
\hline Diff. from baseline & $88.3 \pm 12.9$ & $75 \pm 13.5$ & 0.41 \\
\hline \multicolumn{4}{|l|}{14 th month } \\
\hline Actual value & $1.3 \pm 0.2^{*}$ & $18.1 \pm 7.1$ & 0.06 \\
\hline Diff. from baseline & $89.1 \pm 15.1$ & $71 \pm 14.6$ & 0.42 \\
\hline \multicolumn{4}{|l|}{ 20th month } \\
\hline Actual value & $1.3 \pm 0.2^{*}$ & $23.4 \pm 9.6$ & 0.04 \\
\hline Diff. from baseline & $89.1 \pm 14.4$ & 65.7 & 0.30 \\
\hline
\end{tabular}

* There is a significant difference between groups $(\mathrm{p}<0.05)$.

of psychogenic components in pediatric age group. On the other hand, the belief of a better prognosis for pediatric LDH may limit the number of surgical interventions performed in these cases. Some well-designed previous series provide valuable information on the postoperative prognosis.

The first pediatric LDH case was successfully operated and presented by Wahren [11] in 1945. In 1954, Webb et al. [[12]] reported their operative results of 5 consecutive pediatric LDH cases. Following these initial publications, there were several case reports describing the diagnosis and operative treatment and emphasizing the extraordinary aspects and rare occurrence of $\mathrm{LDH}$ in the pediatric age group.

Some etiological factors in adult LDH can be early disc degeneration and rupture of annulus fibrosus after overload of the spine with failure of posterior ligaments. Various predisposing factors were also suspected in the pediatric LDH cases. A previous trauma or traumatic pathogenesis is the first discovered major difference for pediatric LDH. $25-75 \%$ of the presented cases had a history of trauma. A trauma history was present in $9.3 \%$ (3 patients) of our series. A traumatic etiology may be suspected for pediatric LDH cases. Otherwise the control group in the present study also had a $12.5 \%$ rate of trau- 
ma history. Gender is the other major concern in the etiology. The female pediatric group has more preponderance to LDH. This may be linked to earlier bony and ligamentous maturation of girls. The other underlying predisposing factor in pediatric $\mathrm{LDH}$ is sports injury and sport-related traumas. A spinal abnormality such as disc disease was found at a high prevalence $(9-63 \%)$ in athletes or swimmers in one previous study [13]. Such a background was present as higher percentage in the pediatric group of the present study (12.5\%). Due to their young age, pediatric cases have a much lower rate of accompanying degenerative changes of the spine such as facet joint degeneration, multilevel lumbar disc degeneration, hypertrophy of yellow ligament and microinstability. These degenerative factors may ensure a benign course of pediatric LDH when compared with adult series. The VAS and ABPS difference after the third month may reflect the painful condition of the degenerative spine in adult group. The presence of a connective tissue disorder and obesity may be other predisposing factors in pediatric $\mathrm{LDH}[6,14]$.

The segmental distribution of pediatric $\mathrm{LDH}$ is similar to that seen in adults. The L4-5 and L5-S1 levels represented the majority of the segments in the presented series. This distribution of segments with pathology was similar in our series. The presenting symptoms of pediatric LDH start with sudden back pain and lower extremity radiculopathy. Otherwise children commonly provide a less specific description of pain than do adult cases. This may be a reason of the diagnostic difficulty with delay for surgical intervention. There are some authors that report a more severe clinical picture in pediatric cases [15], but the others have generally reported a less severe clinical picture than adults $[3,6]$. The clinical picture in children and adults was similar in our cases. The neurological deficit as pure motor loss was minimal in the pediatric cases. Low back pains, severe sciatica, reflex loss and paresthesias on the affected dermatomes were common symptoms in both groups.

Only few reports discuss the efficacy of pain reduction without surgical intervention with regard to conservative management. The reports show a $40-50 \%$ success rate with conservative management $[16,17]$. Pediatric LDH can be safely managed nonsurgically in the absence of a neurological deficit according to previous reports $[5,18]$. However, surgical evacuation is indicated if the patient has a neurological deficit or refractory pain with conservative treatment especially for more than 3 months. The early outcome of surgery in pediatric $\mathrm{LDH}$ is mainly satisfactory. Shillito [5] has found that $96 \%$ of patients show complete relief of symptoms. Grobler et al. [19] reported an $88 \%$ recovery rate in pediatric $\mathrm{LDH}$ cases younger than 15 years of age. Parisini et al. [20] also followed pediatric cases for a long period and emphasized that the outcome was excellent in more than $93 \%$ of the cases immediately after the discectomy, decreasing with time to $87 \%$ at the end of the 12th year during the follow-up period. There is no comparative data in the previous studies [21]. The case numbers are small in some studies and some of the studies were performed in the pre-MRI era.

Two main results emerged from our study after satisfactory follow-up in our case series: first the recurrence rate and peridural fibrosis are significantly lower in the pediatric group, and second the clinical recovery is faster and better in pediatric group. Both results are new and have not been previously mentioned in the literature. This situation may be dependent on the more elastic architecture of the pediatric disc tissue or richer vascular supply of end-plates than adult cases. This result is also interesting and may depend on the factors mentioned above regarding the behavior of the growing spine and low maturity of the muscular system. Both results should be confirmed by more studies on pediatric LDH in the near future.

\section{References}

1 Slotkin JR, Mislow JMK, Day AL, Proctor MR: Pediatric disc disease. Neurosurg Clin N Am 2007;18:659-667.

2 Çelik SE, Çelik S, Kara A, İnce İ, Göksu K: Lumbar facet joint angle and its importance on joint violation in lumbar microdiscectomy. Neurosurgery 2008;62:168-173.

3 Garrido E, Humphreys RP, Hendrick EB, Hoffman HJ: Lumbar disc disease in children. Neurosurgery 1978;2:22-26.

Better Neurological Outcome in Pediatric Lumbar Microdiscectomy
4 Cahill KS, Dunn I, Gunnarsson T, Proctor MR: Lumbar microdiscectomy in pediatric patients; a large single-institution series. J Neurosurg Spine 2010;12:165-170.

5 Shillito J Jr: Pediatric lumbar disc surgery. 20 patients under 15 years of age. Surg Neurol 1996;46:14-18.

-6 Martinez-Lage JF, Cornejo VF, Lopez F, Poza M: Lumbar disc herniation in early childhood - case report and literature review. Child Nerv Syst 2003;19:258-260.
7 Kotil K, Akçetin M, Bilge T: Cauda equina compression syndrome in a child due to lumbar disc herniation. Child Nerv Syst 2004;20: 443-444.

$\checkmark 8$ Kumar R, Kumar V, Das NK, Behari S, Mahapatra AK: Adolescent lumbar disc disease; findings and outcome. Child Nerv Syst 2007; 23:1295-1299.

>9 Martinez-Lage JF, Robledo AM, Lopez F, Poza M: Disc protrusion in the child. Child Nerv Syst 1997;13:201-207.

. 
10 Ross JS, Obuchowski N, Modic MT: MR evaluation of epidural fibrosis: proposed grading system with intra- and inter-observer variability. Neurol Res 1999;21(suppl 1):23-26.

$\checkmark 11$ Wahren H: Herniated nucleus pulposus in a child of twelve years. Acta Orthop Scand 1945;16:40-42.

12 Webb JH, Svien HJ, Kennedy RL: Protruded lumbar intervertebral disks in children. J Am Med Assoc 1954;154:1153-1154.

$\checkmark 13$ Goldstein JD, Berger PE, Windler GE, Jackson DW: Spine injuries in gymnasts and swimmers. An epidemiologic investigation. Am J Sports Med 1991;19:463-468.
4 Conforti R, Scuotto A, Muras I, Cervone de Martino M, Riccio V, Bernini FP: Herniated disk in adolescents. J Neuroradiol 1993;20: 60-69.

15 Kurihara A, Kataoka O: Lumbar disc herniation in children and adolescents. A review of 70 operated cases and their minimum 5-year follow-up studies. Spine 1980;5:443-451.

16 Zamani MH, MacEwen GD: Herniation of the lumbar disc in children and adolescents. J Pediatr Orthop 1982;2:528-533.

17 Kurth AA, Rau S, Wang C, Schmitt E: Treatment of lumbar disc herniation in the second decade of life. Eur Spine J 1996;5:220-224.

-18 DeOrio JK, Bianco AJ Jr: Lumbar disc excision in children and adolescents. J Bone Joint Surg Am 1982;64:991-996.
9 Grobler LJ, Simmons EH, Barrington TW: Intervertebral disc herniation in the adolescent. Spine 1979;4:267-278.

20 Parisini P, DiSilvestre M, Greggi T, Miglietta A, Padoni S: Lumbar disc excision in children and adolescents. Spine 2001;26:19972000.

-21 Durham SR, Sun PP, Sutton LN: Surgically treated lumbar disc disease in the pediatric population - an outcome study. J Neurosurg 2000;92(suppl):1-6. 